Reviewed Article: Teaching and Learning in Clinic

'First they tell us to ignore our emotions, then they tell us to reflect': The development of a reflective writing pedagogy in clinical legal education through an analysis of student perceptions of reflective writing.

\title{
Rachel Spencer*
}

University of South Australia

\section{Rachel.Spencer@unisa.edu.au}

\section{ABSTRACT}

The use of reflective writing has long been recognised as an important component of clinical legal education pedagogy, not least because it provides an important link between the twin pillars of CLE. However, current literature about reflective writing exposes a gap about student perceptions of reflective writing.

This article provides an analysis of the results of formal research that was conducted into student perceptions of reflective writing in the clinical legal education context. The research was designed to investigate whether students perceived any benefit from reflective writing and what difficulties they actually encountered in writing in a way that is particularly different to other forms of academic assessment. This article focusses on student perceptions of the benefits of reflective writing. A further aim of the research was to develop an improved pedagogy of reflective writing in the clinical legal education context. The article concludes that students perceive 
limited benefits from reflective writing and offers several suggestions and recommendations as to how this limited perception might be enhanced.

Key words: pedagogy; reflective writing pedagogy; clinical legal education; reflection; teaching and learning framework

\section{PART I: INTRODUCTION AND BACKGROUND}

The twin pillars of clinical legal education are the pedagogical benefits of students being able to provide legal advice to 'real' clients, and the social justice component of providing legal services to those in society who might otherwise be denied access to justice through a lack of legal advice. ${ }^{1}$ The use of reflective writing has long been recognised as an important component of clinical legal education pedagogy, not least because it provides an important link between the two pillars.

This article provides a sequel to my previous research about teaching students to be reflective. ${ }^{2}$ Readers are referred to that earlier article for a comprehensive literature review of the pedagogy of reflective learning and reflective writing ${ }^{3}$ which will not

\footnotetext{
* Rachel Spencer is the Director of Professional and Clinical Programs in the School of Law at the University of South Australia. I would like to acknowledge and thank the two anonymous reviewers of this article whose suggestions for refinement were extremely helpful.

${ }^{1}$ See for example, Curran, L, Dickson, J and Noone M A, 'Pushing the Boundaries or Preserving the Status Quo: Designing Clinical Programs to Teach Law Students a Deep Understanding of Ethical Practice' (2005) 8 International Journal of Clinical Legal Education 104; and Ojienda T.O. and Oduor M. (2002) 'Reflections on the Implementation of Clinical Legal Education in Moi University, Kenya', 2 International Journal of Clinical Legal Education 19, 51. See also Bloch Frank S (Ed) (2010) The Global Clinical Movement: Educating Lawyers for Social Justice, Oxford University Press.

${ }^{2}$ Spencer, R. (2012) 'Holding Up the Mirror: A theoretical and practical analysis of the role of reflection in Clinical Legal Education', 18 International Journal of Clinical Legal Education 179-214.

${ }^{3}$ Spencer, above.
} 
be repeated here but can be summarised by Kennison's observation that '[s]uccessful use of reflection as an effective pedagogy for clinical teaching is dependent on a supportive teacher who knows how to facilitate the process. ${ }^{4}$ The purpose of this article is to consider and respond to the questions that were raised by my earlier research. In particular, the research about the pedagogy of teaching reflective writing exposed a gap about student perceptions of reflective writing. Do law students like reflective writing? Do they find it difficult? Is it helpful? An examination of the vast scholarship about reflection and reflective writing has been informative and instructive in relation to the development of teaching philosophy and pedagogy ${ }^{5}$ and it has generated new developments in my own teaching practices. However, having analysed why reflection is a positive influence on student learning and professional development, especially in the Clinical Legal Education context, and having considered the opinions of a number of authors, teachers and clinicians ${ }^{6}$, it was clear that to date there has been a gap in the literature concerning student perceptions of reflective writing. It appears that scholars have not surveyed students about their views on reflective writing.

One of the attributes of reflective writing is the 'licence to write in the first person' and, as I did in my earlier article, I have deliberately adopted this technique in this article.

\footnotetext{
${ }^{4}$ Kennison, M (2012) ‘Developing Reflective Writing as Effective Pedagogy', 33 (5) Nursing Education Perspectives, 306.

${ }^{5}$ See Spencer, above n2.

${ }^{6}$ Spencer, above, $\mathrm{n} 2$.
} 
Students in my Clinical Legal Education course are required to reflect not only on their placement experiences but also to link their experiences to articles about specific issues. Students are encouraged to write often, and to re-write their journal entries as the term progresses so that they can add layers of insight to their thoughts. This aspect of the reflective learning pedagogy encompasses the pedagogy of the New Rhetoric, a less formal approach to writing. ${ }^{7}$ Sometimes the student focuses on her role as a reader, at other times, the focus is on the student as writer. The students are encouraged to engage in dialogic reflection by engaging in a dialogue with their various selves (as readers and writers) and also with the audience (the teacher / assessor). ${ }^{8}$ The goal of the reflective writing process is 'to encourage students to view their early readings and writings as tentative drafts that are open to change; to build in pauses when the student-as-reader or the student-as-writer can reflect on current meaning, goals, and plans; and to give students contextually based rhetorical choices to move forward. ${ }^{\prime 9}$

While it is recognised that the clinical approach gives students a chance to experiment with the theoretical knowledge they have as they can discuss what they are learning and experiencing with other students, advocates or members of the

\footnotetext{
7 The New Rhetoric is further discussed in the sequel to this article, Spencer R. (2014) 'Private Lives: Confronting the inherent difficulties of reflective writing in clinical legal education', 21(2) International Journal of Clinical Legal Education. See also Kowalski, T. 'Toward a pedagogy for teaching legal writing in law school clinics,' (2010-2011) 17 Clinical Law Review, 285, 311.

${ }^{8}$ See Berger, Linda, (1999) 'Applying New Rhetoric to Legal Discourse: The Ebb and Flow of Reader and Writer, Text and Context' in 49 Journal of Legal Education 155, 169.

${ }^{9}$ Berger, above, 169 .
} 
bench, ${ }^{10}$ reflection also gives students the opportunity to question their own actions, motives and responses. The skill of reflection extends clinical legal education into far more than 'learning law by doing law' ${ }^{11}$ However, more than a decade of clinical legal teaching has also informed me that student attitudes to reflective writing are varied and complex. In addition, students have a range of attitudes towards the usefulness and validity of reflective writing. Anecdotal evidence over many years (from conversations with individual students and classroom discussions) has suggested that students generally find reflective writing difficult at first, but over time they come to value the skills involved in reflection and the extra dimension that it provides to a clinical placement experience. Of relevance also is the fact that the majority of current law students are part of 'Generation $Y^{\prime}$ or 'The Millennials' (born between 1982 and 2002). ${ }^{12}$ The learning styles of this generation have been noted to be different from those of earlier generations, most particularly because they have grown up with digital media as a constant presence in their lives, and also because they may be 'the most supervised and scheduled child generation ever. ${ }^{13}$ Members of Generation $\mathrm{Y}$ have been found to be kinaesthetic learners ${ }^{14}$ who prefer active learning, structure and teamwork, accompanied by an increased emphasis on skills

\footnotetext{
${ }^{10}$ See Ojienda T.O. and Oduor M. (2002) 'Reflections on the Implementation of Clinical Legal Education in Moi University, Kenya', 2 International Journal of Clinical Legal Education 49, 50. ${ }^{11}$ Ojienda and Oduor, above, n 3, at 49, and Grimes, R. (2000) 'Learning Law by Doing Law in the UK', 1 International Journal of Clinical Legal Education, 54.

${ }^{12}$ Carver, T, (2011) 'Peer Assisted Learning, Skills Development and Generation Y: A Case Study of a First year Undergraduate Law Unit, 37 (3) Monash University Law Review, 203, 204.

${ }_{13}$ Neil Howe \& William Strauss, (2000) Millennials Rising: The Next Great Generation, 134, Vintage

Books, cited in Carver above, 205.

${ }^{14}$ Carver, above n 12, 206.
} 
development, or process over content.' ${ }^{15}$ It was considered important to ascertain the attitudes of current students towards reflective writing, given that it is a predominantly solitary and extremely personal activity.

But does the process of being forced to reflect really make students more reflective about other tasks, their work and other aspects of their lives? The research aimed to identify whether reflection-in-action in a professional context is likely to take place after a clinical legal education experience.

Part II of this article identifies the aims and objectives of the research that I carried out. Part III of this article explains the research methodology which involved two forms of data collection. Individual students were asked to provide responses to a questionnaire. All students who responded to the questionnaire were also invited to participate in a focus group in order to supplement the data obtained from the questionnaires. Part IV offers an analysis of the data that was obtained from the research. Part V offers conclusions that can be drawn from the research and a series of recommendations for the development of a reflective writing pedagogy, including some innovations that I propose to implement.

\section{PART II: AIMS AND OBJECTIVES OF THE RESEARCH}

The aim of the research was to identify student perceptions about reflection and reflective writing as an assessable component of the clinical course ${ }^{16}$ which I teach. I

${ }^{15}$ Carver, above, n 12, 206. 
consider this to be an important aspect of the teaching-research nexus which underpinned the establishment of the Legal Advice Clinic which is where most students complete their clinical placement for the course. One of the aims of the course is to develop and improve self-awareness in law students, as a means of providing a coping mechanism for stressful situations. The need for such programs has been identified in the literature. ${ }^{17}$ Reflective writing is considered to be an important part of the development of self-awareness but the research aimed to explore student attitudes about this.

In particular, the objective of the research was to ascertain whether student perceptions of reflective writing match faculty perceptions of the benefits of reflective writing in clinical legal education. There were three main aims:

- To ascertain the perceived benefits of reflective writing from a student perspective.

- To ascertain the sources of student anxiety in relation to reflective writing.

- To develop an improved pedagogy of reflective writing in the clinical legal education context.

Much has been written about the value of reflective practice in a professional context. Teaching structured reflective practice in a clinical context is said to assist

\footnotetext{
${ }^{16}$ At the writer's university, each 'subject' is called a 'course'. Some universities use the term 'unit' or 'topic'. In this article, the term 'course' will be used.

17 See, for example, James C (2008), 'Lawyer Dissatisfaction, Emotional Intelligence and Clinical Legal Education', 18 Legal Education Review 123, 135.
} 
with the development of reflective practice and reflection in action ${ }^{18}$ after graduation. Evans et al also emphasise that reflection in a clinical setting assists students in the development of responsibility, resilience, confidence, self-esteem, self-awareness, courage and humility. ${ }^{19}$ Although the benefits of reflective writing have been well documented, there is a gap in the clinical legal education literature in relation to whether or not law students actually do find reflective writing to be a positive experience. I considered it important to ascertain student attitudes towards reflective writing in order to 'sell' reflective writing to future students. I believe that explaining the attitudes of past students to current students is an important part of clinical pedagogy. Knowing that some students found reflective writing to be a negative experience, I wanted to formally explore the reasons for the negativity in order to address them.

My research started from the premise that there appear to be three key assumptions inherent in the expectation of clinical legal educators that students will write an assessable reflective analysis of their clinical placement. The first assumption is that students know how to reflect and that reflection is a natural innate skill. In a previous article ${ }^{20} \mathrm{I}$ have expressed the view that students need to be taught how to reflect, and clinical teachers must teach the skills of reflection before students are

\footnotetext{
${ }^{18}$ Evans, A, Cody, A, Copeland, A, Giddings, J, Noone MA, Rice, S and Booth, E (2013) Best Practices: Australian Clinical Legal Education, Office for Learning \& Teaching, Department for Industry, Innovation, Climate Change, Science, Research and Tertiary Education, esp. pp 34, 44, 50, 56, 58.

${ }^{19}$ Evans et al, above, p 58 .

${ }^{20}$ Spencer, above $\mathrm{n} 2$.
} 
able to reflect effectively. ${ }^{21}$ On the understanding, therefore, that students need guidance on how to reflect, I wanted to ascertain student attitudes towards reflective writing. The second assumption which underlies the expectation that students will produce an assessable piece of reflective writing is that students actually want to reflect. Anecdotal evidence and corridor discussions with students suggested that students have a level of concern about reflective writing that is being ignored by clinical teachers and others who require students to produce assessable reflective writing. A formal enquiry was considered necessary to unearth such concerns so that they might be addressed.

A third assumption is that students find reflection a useful and positive experience and that reflection enhances the placement experience. The literature strongly argues that it does. In addition to the desired goal of enhancing the placement experience, one of the aims of the development of the skill of reflective writing is to provide students with a useful skill. But I wanted to know whether students find reflective writing to be useful. I wanted to find out whether pedagogical perceptions of usefulness matched student perceptions of usefulness. Further, if students do not find reflective writing to be useful, why not? I also wanted to examine whether or not students perceive reflective activity as enhancing their clinical placement experience. I wanted to understand the reasons why some students are finding that reflective writing does not enhance the placement experience. The research aimed to

\footnotetext{
${ }^{21}$ See Spencer, above, n2, especially pages 187-203.
} 
identify possible improvements in the way that reflective writing is taught in order to enhance both the perception and the actuality of usefulness.

This research is not only important for clinical educators. Reflective writing as an assessable component of law courses now extends beyond clinical programs and is widely used in a variety of subjects. In the writer's own Law School, for example, reflective reports and other forms of assessable reflective writing are required in a number of introductory first year law courses (such as Contract Law), as well as in later year courses (such as Evidence) and elective courses (such as Family Law).

\section{PART III: APPROACH AND METHODOLOGY}

The research design envisaged that all students enrolled in my Clinical Legal Education course would be asked to respond to a survey about reflective writing. I conducted qualitative research by way of a personal questionnaire. Approval from the relevant University Ethics Committee ${ }^{22}$ was sought and obtained to distribute questionnaires to students enrolled in my Legal Professional and Community Service Experience course. This is a clinical legal education course where students are placed at a variety of external placement offices or within the School of Law's own Legal

\footnotetext{
${ }^{22}$ Human Research Ethics Committee at the University of South Australia.
} 
Advice Clinic. A comprehensive description of the assessable reflective practice exercises in my course is provided in my earlier article..$^{23}$

My law school operates on a trimester system, in which the academic year is divided into three terms. The clinical legal education course is offered as an elective course each term. I am the course-co-ordinator and I teach the course for two out of three terms every year. However, in 2013, I did not teach or co-ordinate the course in Terms 1 and 2, and a different member of staff performed this role. A questionnaire was handed out to all students present in the last class at the end of each term for four consecutive terms (Terms 1, 2 and 3 in 2012 and term 1 of 2013). Students were provided with an information sheet about the research that was being conducted and invited to participate by writing answers to the questions on the survey sheet. Not all students enrolled in the course were present during the time of the questionnaires being handed out, so the responses are not representative of the entire student cohort from each term. However, all students present each time filled out the questionnaires. It was made very clear that it was a voluntary activity. No student declined to complete the questionnaire.

Across the period of four terms, there were a total of 51 students enrolled in the course. ${ }^{24}$ Out of 51 students, 28 students completed the questionnaire, representing $54.9 \%$ of the enrolled students across that period of time. The answers to the

\footnotetext{
${ }^{23}$ Spencer, above, $\mathrm{n} 2$.

${ }^{24}$ A total of 8 students in Term 1 2012; 17 students in Term 2 2012; 9 students in Term 3 2012; 17 students in Term 12013.
} 
questionnaire were handwritten and then submitted to me. All responses were anonymous and so student participation could have no bearing on their assessment in the course.

The questions were:

1. Have you found keeping a reflective portfolio to be a positive or negative experience? Why?

2. Do you find reflective writing easy or difficult? Explain.

3. Have you found writing a reflective journal to be a useful exercise? Why or why not?

4. Has the process of being forced to reflect made you more reflective now about other tasks/ work/aspects of your life?

5. Has the process of reflection enhanced or detracted from your placement experience? Please explain your answer.

6. Have you been worried / frustrated / concerned about reflective writing? Please elaborate.

7. Please provide any other feedback you have about the reflective writing component of this course.

After completing the questionnaires, students were also invited to attend a focus group to speak in more detail about their experiences of reflective writing. Nine students participated in a focus group. ${ }^{25}$ The focus group discussion was recorded on a digital audio-recorder and the results transcribed. Students participating in the focus group were provided with a copy of a 'Participants' Information Sheet' which outlined the aim of the research, the fact that responses were confidential and that

${ }^{25}$ On 4 April 2013. 
participation was voluntary. Participants also signed a Consent Form acknowledging that they were participating voluntarily and that their responses would be de-identified. Approval was obtained from the University Human Research Ethics Committee to conduct the focus group. All students who attended the focus group had already been assessed in the course so there was no question of student participation having any bearing on their grades. I conducted the focus group, which was an informal occasion with a pleasant atmosphere. Students who agreed to attend the focus group were aware that I would be conducting it. I considered whether my presence would influence the results but the students who attended were very frank and forthright with their comments, and appeared to appreciate the opportunity to discuss their views. I do not believe that my presence affected the results in any way.

Although some quantitative analysis has been conducted in relation to the responses, the research was predominantly a qualitative study of student responses to the seven questions.

This article provides an analysis of the responses to questions 1, 3 and 4 and focusses on whether or not students found reflective writing to be a positive or negative experience. It also examines student perceptions of the usefulness of reflective writing as an ongoing life-long learning skill. The responses to questions 2, 5 and 6 
pinpoint specific difficulties identified by students as inhibitors to reflective writing. These responses are analysed in a separate article. ${ }^{26}$

\section{PART IV: RESULTS OF THE RESEARCH \& CONCLUSIONS}

This part sets out a detailed analysis of the responses to the survey questions 1,3 and 4 and the data obtained from the focus group. Analyses of the responses to each question are provided sequentially.

IV (i) Question 1: Have you found keeping a reflective portfolio to be a positive or negative experience? Why?

Out of 29 written responses to this question, 24 students specifically stated that they found keeping a reflective portfolio to be a positive experience although they expressed different reasons for this. Four students stated that they found it to be a negative experience. One stated a 'neutral' position.

The responses to Question 1 provide a useful insight into why most students find reflective writing to be a positive experience. Several of them used words like 'focus', 'interesting', 'beneficial', 'it helps me', 'sense of direction' and 'great'. This discourse suggests that students are able to identify specific reasons for deciding that reflective writing is a positive experience. The discourse employed by many students is suggestive of reflection-on-action having the potential to develop into reflection-

\footnotetext{
${ }^{26}$ Spencer R. (2014) 'Private Lives: Confronting the inherent difficulties of reflective writing in clinical legal education', 21(2) International Journal of Clinical Legal Education.
} 
in-action ${ }^{27}$. Expressions like 'a view to improve', 'long term effect', 'in the long run', 'a great habit / experience to learn', 'a sense of direction', 'keep tabs on my work and progress' all imply that reflection is something which might be considered beyond the bounds of the course and into the future.

Student responses to Question 1 identified a number of reasons as to why they found reflective writing to be a positive experience, including the ability to be objective about their own progress and development. This is evident in the students' terminology which identifies the opportunity for objectivity as a positive aspect of reflective writing. For example, the ability to 'look back' on their experiences was regarded positively by a number of students, as was being able to 'see how I have developed'. The ability to learn from experiences was strongly favoured, as was the opportunity to focus on achievements. For example, one student said:

Forcing yourself to take a step back $\mathcal{E}$ analyse yourself, your effect on others $\mathcal{E}$ particular events with a view to improve $\mathcal{E}$ reflect on how others perceive situations $\mathcal{E}$ the long term effect of such is very interesting. It also allows you to take stock of things $\mathcal{E}$ remove yourself from the scenario for a greater depth of analysis.

One dominant theme was the positive reaction to self-awareness as part of professional development. Several students referred to their 'development', a 'sense of direction', 'what I need to improve on' and the ability to 'learn from experience'. This discourse suggests personal satisfaction and a demonstrated sense of

${ }^{27}$ Schön, D.A. (1983) The Reflective Practitioner: How Professionals Think in Action, USA: Basic Books. 
achievement. These types of comments are very introspective and indicative of a level of self-awareness that is desirable for the development of emotional intelligence. The experience is described as positive from a personal point of view; the use of personal pronouns is a recurring theme, indicative of a recognition that the reflective writing process is personal and idiosyncratic. For example:

It allows me the chance to reflect back on my portfolio and see how I have developed and grown.

It helps me focus at placement $\mathcal{E}$ focus on learning at placement, instead of worrying that I'm not performing well enough, then it helps me organise what I've learnt once I've got home.

I have found it to be very beneficial for me on a personal level. I think that it is not easy to know how much you have learnt or grown without reflecting.

The concept of 'focus' was a common theme. Several students liked the fact that reflective writing created order for them:

\author{
it helps me focus \\ it helps me organise what I've learnt \\ it allowed for me to keep tabs on my work and progress
}

Interestingly none of the questionnaire responses indicated an adverse reaction to writing in the first person, a critical element of reflective writing which has been noted to be contrary to traditional legal discourse which is 'clear, orderly, linear, 
objective and rational.' ${ }^{28}$ Although this was not specifically asked in the questionnaire, it is noteworthy that no students raised it as an issue of frustration or concern. However, students in the focus group did raise this as an issue.

The keeping of a reflective journal has been mentioned in the literature as a means of developing emotional intelligence. ${ }^{29}$ One student specifically commented on reflective writing as a positive experience in the context of emotional reactions to issues on placement:

It also gave me an output for my emotions - as some of my experiences on placement I found to be quite emotional.

Another student mentioned 'feelings':

It has been positive to reflect on my learning, outcomes, feelings and my growth from the differing situations experienced on placement / uni.

Several students raised negative issues. However, the negative comments tended to be in the context of initial hesitation at the start of the reflection process. Many students articulated some sort of struggle at first, followed by a deeper understanding and appreciation once the writing process was over, for example:

\footnotetext{
${ }^{28}$ Berger, above, $\mathrm{n} 8$.

${ }^{29}$ See, for example, Spencer, above, n 2; James C, 'Seeing Things As We Are. Emotional Intelligence and Clinical Legal Education,' (2005) 8 International Journal of Clinical Legal Education 123; Pololi LP and Frankel RM, 2001 'Reply to 'Vanquishing Virtue': The impact of medical education,' Acad Med 17(12):1172; Duke S and Appleton J, 'The use of reflection in a palliative care programme: a quantitative study of the development of reflective skills over an academic year', 2000 Journal of Advanced Nursing, 32(6) 1557-1568.
} 
It was a little annoying to try to keep up with it each week, however it is more beneficial in the long run.

Initially I viewed it as a chore, but having done it, I now see the benefit as it makes you stop and think about how and why you do things.

The finding that students are initially hesitant, even resistant, to reflective writing reenforces my view that in order to be effective, reflective writing must be practised regularly. Many students seem to recognise the value of ongoing reflective writing practice. One student said described it as:

\section{A great habit / experience to learn}

Students particularly valued the opportunity to monitor their own performance and development. They also appeared to recognise the importance of the difficulties encountered in the early stages of reflection. A number of students employed a discourse that indicated an appreciation of the experience of disorientation or confrontation. Students identified that they need 'disorienting moments' ${ }^{30}$ in order to learn from their experiences. From a student perspective, this may be interpreted as a negative factor but from a pedagogical point of view, these 'disorienting moments' ${ }^{31}$ are important in the clinical experience. This forms part of the reflective writing pedagogy. It is important to let students know that they may experience

\footnotetext{
30 See Quigley F, 'Seizing the Disorienting Moment', 2 Clinical Law Review 37, 51, Aiken JH, 'Striving to Teach "Justice, Fairness and Morality" in (1997-1998) 4 Clinical Law Review 1, 24 and Spencer, above n 2, 193.

${ }^{31}$ Quigley, above.
} 
these negative sensations and feelings as part of the reflective process. This is all part of the 'disorienting moment'.

One student articulated the need for reflection to develop self-awareness:

The more I reflect, the more I become aware of things that happened and how my experiences have shaped me and my thinking.

This is one of the foremost lessons of clinical legal education, to encourage students to consider situations from perspectives other their own, in order to develop empathy. Once the notion of empathy has been understood, then the concept of client-centred practice makes more sense.

Some responses demonstrated Berger's notion of constructing meaning from reading and writing, derived from the need to 'start and continue a conversation' 32 between the student as reader and the student as writer, allowing the student to conduct the 'continuing audit of meaning' that is necessary for critical reading and writing, ${ }^{33}$ for example:

I already reflect constantly on myself. I clearly understand my negatives $\mathcal{E}$ positives in both my personality $\mathcal{E}$ actions. However, making it compulsory requires a deeper analysis than what I usually do.

\footnotetext{
32 Berger, above, $\mathrm{n} 8,172$.

${ }^{33}$ Berger, above, n 8, 37173.
} 
One student commented on the ability to 'look back $\mathcal{E}$ see how far you have come' as a positive aspect of reflective writing. This student also noted that being able to develop your deeper thoughts $\mathcal{E}$ to put them down on paper was a positive activity.

I would say the experience was positive as it provided an outlet for reflection and allows for future recollection - if anything it allowed for me to keep tabs on my work and progress in organising placement.

Some students admitted that they found the task challenging, but that the challenge produced a positive reaction:

Positive experience. The more I reflect, the more I become aware of things that happened and how my experiences have shaped me and my thinking. It's like I'm searching my brain for reasons of why it makes me act in certain ways.

It's a bit of a hassle but I wouldn't go so far as to call it negative. I find I struggle to think of things to write down because when I internally reflect during a situation I don't grab onto an idea ready to write it down later.

Both. Positive because it helped me recognised (sic) why I acted the way I did and helps me learn from that experience. Negative because the depth required (i.e. talking about your actions re: society as a whole) was quite time consuming and at times perplexing.

In relation to the reflective writing experience itself, a number of students used negative descriptors such as 'confronting', 'annoying', 'tedious', 'a chore', 'time 
consuming', 'perplexing', 'difficult', 'intensive', 'challenging' and 'hard'. Others used negative descriptors when describing themselves during the reflective writing experience, such as:

I feel quite awkward and uncomfortable

I was overwhelmed

I dislike writing my thoughts down to share

...it isn't something I enjoy

Some students specifically commented that they had a positive reaction to the act of reflection but a negative reaction to committing reflections to writing on a regular basis:

It was a little annoying to try to keep up with it each week...

I have found the process a little tedious.

...the depth required ... was quite time consuming and at times perplexing.

Some students linked negativity with reflective writing in the context of the assessment scheme:

Rather than being reflective, I care more about the marks that I will get. I give out what I think the lecturers will want rather than being reflective of my personal strengths / weakness. Further, I dislike how our subjectivity is marked in such an objective way. It's demeaning for our personal, emotional and reflective values. 
This concern was discussed in the Focus Group where there was an overwhelming sentiment that there was too much assessable reflective writing. For example:

I don't think there should be that much reflection, not that much for the whole subject...

Others argued that the requirement for critical reflection was onerous and difficult. One student said:

... even for our first assignment when we had to do a reflection on something that happened in the Clinic, she's like, 'Go deeper and deeper and deeper,' and ... I can only go so deep in a thousand words ... You can only go so deep and still relate it to other stuff, you have to get that balance and that balance is really difficult.

Some students expressed frustration that the person marking reflective writing assignments imposed their own subjectivity onto the students' reflections. For example one student in the focus group said:

What I don't like about reflection is that they tell you to write how you feel and how you felt and what you did ... but like you write how you feel and whatever and then it's up to the person marking to say whether what you felt was right.

Another issue raised by several students was that writing a reflective journal necessitated 'finding something to worry about'. One survey respondent commented that: 
It's difficult to just be at placement and take it all in when you have to worry about finding something to worry about.

This is perhaps a misunderstanding about the 'disorienting' moment and perhaps also an indication of a misunderstanding about the required subject matter. An important conclusion to be drawn from this finding is that instructions for the subject matter for reflective writing must be made very clear: critical analysis does not equate to criticising the placement or finding something about which to express negativity. Reflection is not about finding something to worry about. It is about a deep consideration of the student experience from the perspectives of all involved.

IV (ii) Question 3: Have you found writing a reflective journal to be a useful exercise?

Question 3 was designed to probe the assumption that reflective writing is perceived by students as a useful exercise. I wanted to find out whether pedagogical perceptions of usefulness matched student perceptions of usefulness. If students did not find reflective writing to be useful, why not?

Twenty-eight students answered this question. Students articulated various categories of 'usefulness' of reflective writing. The first category of usefulness was in relation to writing skills. Some said that reflective writing was 'a good skill to have'. One student said that reflective writing had 'helped me to develop a new writing style.'

A large number of students mentioned organisation as a key positive factor in the usefulness of reflective writing. For example: 
It has been useful for me as it allows me to keep matters in context. It is somewhat of a natural extension of what I have done internally for many years, now manifest into words.

... it helps me organise what I've learnt. It also helps me to see how I've progressed $\mathcal{E}$ it helps me to see how what I've learnt in class can be applied to the real world.

It has helped me remember what I have done on a daily basis, and helped me identify the skills that I need to work on.

One student said that reflective writing was invaluable for 'life in general' while another found it useful because:

I already keep a journal $\mathcal{E}$ have documented my life since about 13. I did this so if one day I get rich $\mathcal{E}$ powerful, I can publish a biography of how I did it.

The third category of perceived usefulness was in the context of the placement; a number of students said that reflective writing helped in some way with the placement or with the student's own particular professional development. Use of words like 'progress', 'progression', 'development', and 'improvement' were common in this response. A common theme in the responses was an appreciation of being able to self-monitor personal development and progress. Some students said that the reflective journal helped them to overcome an initial lack of confidence, e.g.

Keeping a reflective journal has been a useful exercise because it's allowed me to put on paper my experiences/goals/thoughts at Placement. I've seen myself develop as a "Student Advisor" on paper 
and its (sic) helped me overcome some of my initial fears of Placement, i.e. lack of confidence.

Yes, it was useful in helping me identify aspects of my professionalism that could be improved.

Very beneficial for learning. Your (sic) able to see where you've come from and then build on certain skills to improve them. For me, it is always about improvement - and I've certainly found that by keeping a reflective journal I am able to do this.

One student commented that it was 'useful to be able to get everything on paper... My reflections would probably be useful if I went back and looked them and thought how they could help my work experience.

Another student found that reflective writing enabled the creation of 'a record of my thoughts and reflections' which enabled the student to 'consider them more carefully $\mathcal{E}$ bring them to the front of my mind.' This student recognised that this enabled more careful consideration than a 'fleeting' reflective thought would have otherwise engendered. There were several comments indicating an appreciation of reflective writing as an exercise in critical thinking. Critical analysis of the placement was seen as a useful and beneficial exercise by some students, adding value to the placement experience 'instead of simply going through the motions'. One student commented on the readings provided as part of the course: ${ }^{34}$

\footnotetext{
${ }^{34}$ The readings are scholarly articles, mostly by clinical legal educators, about access to justice, clientcentred practice, empathy, emotional intelligence, law reform, the role of lawyers and legal ethics. Some articles about reflective writing are also provided.
} 
Using the articles we read really helped with the reflecting. It expanded our thoughts \& the issues we reflected on.

Yet another student appreciated that keeping a reflective journal enabled critical thinking about 'how I would have dealt better or react to the incident, identify ways of improvement in case it happens again in the future.'

The fourth category of perceived usefulness was in relation to dealing with clients. For example, one student said:

It was useful in the sense that I was able to relate it to the clients I dealt with. However, in some respects I felt I was becoming too pretentious and it detracted from talking about the ethics and skills involved in placement.

Finally, the fifth category of perceived usefulness was applying theory to practice. A number of students identified that making notes of placement experiences assisted with learning 'how the Law is applied in the 'real WORLD'.

Four out of 29 students did not find writing a reflective journal to be a useful exercise. These students said that keeping a journal was not necessary to facilitate reflection. However, they all made the comment that they were able to reflect and that they believed that reflection was important. But they did not see the necessity to actually record their reflections. I explored this further in the Focus Group. One student in the Focus Group said: 
You sort of more understand with another subject, maybe like Psychology or something like that but ... to go as deep as we're required to it's just... a bit of a pain in the butt to be honest. You go to a certain point and then ... it's just like, really, you know, I know it's supposed to be helping us, and it does in a sense, but, maybe not to the extent that we're required to, I don't think it's helping. I don't think that it's beneficial to me, in that way, to be honest.

IV (iv) Question 4: Has the process of being forced to reflect made you more reflective now about other tasks / work / aspects of your life?

Out of 29 responses, 15 responses to this question were negative. This suggests that reflection-in-action might not be something that will immediately become part of professional life. This finding demonstrates that even though most students find reflective writing to be useful (refer to responses to Question 3), they may not necessarily use the skill of reflection beyond the course. On the other hand, a number of the responses indicate that they may be reflective in other aspects of their life, but not because of having to reflect for this course.

Some responses suggest that having to reflect in the course will not have an impact on other aspects of life:

No. I have never enjoyed reflection to a great extent, so therefore it has not changed how I do things and look back on things. I do reflect on some things, but not any more than I did before. 
Other responses suggested that the students will continue to reflect - many were at pains to point out that they do reflect already - but that the reflective components of the course have not been the catalyst for this.

I was already quite reflective before. Although it is possible that it has helped me organise my reflections better at times.

I have always been a reflective person so it hasn't really affected other aspects of my life.

I already reflect in my head and think about ways things could have happened differently.

I'm an expert at critical self analysis $\mathcal{E}$ reflection already.

A Focus Group member said:

I honestly think we all do it subconsciously anyway. It's sort of like, after you do something, you always think about, 'I should have said that, I should have done that.' You always do it anyway so I honestly don't think that it makes a difference.

However, although some students may be naturally reflective, I am not convinced that all students and all lawyers do think about their words and actions after having done something. In addition, such students could benefit from the development of this skill. For me, this highlighted the need to emphasise the advantages of reflection by using prompts for reflective writing ${ }^{35}$ to enhance the quality of reflection.

\footnotetext{
${ }^{35}$ See Spencer, above, n 2, p 198 \& 208 and J.P. Ogilvy, 'The Use of Journals in Legal education: A Tool for Reflection' in (1996-1997) 3 Clinical Law Review 55 at 100 from a presentation by Paul Hettich, Journal Writing for Teaching and Learning in Psychology at the 99th Annual Convention of the American Psychological Association (San Francisco, CA 1991).36.
} 
Some students openly declared that the process of being forced to reflect has not made them more reflective now at all and that they will not be reflecting more in the future. One student said:

This is simply because I don't have time to think about and act reflectively.

In my previous work experience I have worked in an industry where you learn on the go and are required to learn quickly. Sitting down and writing about it is not something I've found to be overly beneficial.

Not necessarily, at times may think / over-analyse things but not on the whole.

These responses suggest that more needs to be included in the clinical teaching program about the benefits of reflection-in-action and that more of the literature on this needs to be discussed in class in addition to simply including texts and articles in the student reading lists. Suggestions for implementation of this idea are included in Part V.

However, some students did say that they would now be more reflective in other aspects of their lives. These students commented on the dialogic aspects of reflective writing, in particular, the ability to consider a situation from multiple perspectives. They used expressions that highlighted new levels of self-awareness, like being 'especially aware' and 'more conscious': 
...especially aware of how others may perceive my actions or their impact...

...more conscious of my reflections ... now I think more about thinking.

Yes, especially when reflecting about other peoples (sic) perspectives of certain issues. I've noticed that I have automatically been doing this all the time now, at soccer, work, at home etc.

It will probably force me to look at things from an outsider's perspective.

Other students drew a link between reflection and their own personal or professional development. One student said that being forced to reflect had crystallised the importance of reflection in order to grow \& develop as a person. Reflection was now 'almost an automatic action' for this student. Another comment was that the requirement to analyse and discuss the placement allowed the student 'to see where I am within the profession - having nearly finished my degree.' Reflection was also seen as a means of identifying skills...combined with personality and interests. This was seen as important for assisting with the identification of desirable employment after graduation.

...this reflective learning component allows for self awareness and therefore change, deep thinking, reflecting on other areas of your life, improves life skills.

Many students used language indicating that reflection is something that would form part of their life or work after the clinical placement. One student said that 
reflection was now almost an automatic action. Another said 'now I think more about thinking.' Another student found that reflection was so useful it had now become part of daily life:

... ever since I realised the benefits of reflecting, I have started my own life reflections every night of all the good things I did that day and all the bad things I did so that way I am aware of my daily actions. Although its (sic) very brief it still helps a lot and has improved the quality of my life.

I can see how it would be useful $\mathcal{E}$ beneficial for future aspects at law school.

...to a certain degree I now employ my reflective skills in other tasks.

...it is likely to be beneficial for other aspects of my life, because I am able to look back at past experiences and improve myself.

I've noticed that I have automatically been doing this all the time now, at soccer, work, at home etc.

I feel the whole process and the course was invaluable. In relation to the journal the best aspect was relating my tasks and works / life to the journals of others and articles written by professionals. Having to analyse and discuss within my journal allowed me to see where I am within the profession - having nearly finished my degree.

It will be useful for future students in my course to be aware of the benefits that past students have obtained and perceived from reflective writing. These will be incorporated into future classes. 
Research has shown that students are strategic learners and their focus tends to be on issues which will be assessed. ${ }^{36}$ A number of the responses to Question 4 reinforced this. Several answers suggested that the students reflected because this was required for assessment, but did not value the process of reflection in itself. For example, one student said that the assignment submission was '[n]ot really reflecting, just telling the marker what they want to hear.'

Strategies need to be developed to not only teach students how to reflect and how to write reflectively, but also to articulate the value of reflection. Perhaps the word 'reflection' itself has developed a somewhat negative image. It may be the case that competitive law students would prefer to engage in an exercise entitled 'placement analysis' or 'personal deliberation' or 'achievement analysis' rather than 'reflection'. Time spent in class discussing Schön's work would likely be beneficial and useful for students who question the value of reflective writing.

\section{PART V: CONCLUSIONS AND RECOMMENDATIONS}

The research unearthed a variety of issues to be addressed in order to enhance reflective writing pedagogy. Where concerns and anxieties have been raised it is hoped that these can be reduced or eliminated. Some of the students' responses raised issues that I had not previously considered. This has informed my teaching

\footnotetext{
${ }^{36}$ Ramsden P (2013) Learning to Teach in Higher Education, Routledge, London, p53; Entwistle, N (1981) Styles of Learning and teaching: An Integrated Outline of Educational Psychology for Students, Teachers and Lecturers, Wiley, Chichester, p 103, cited in Holland below, n 58, p 27.
} 
practice and indeed has added to the scholarship of teaching and learning in this area.

\section{The value of reflection}

The research shows that students value the reflective writing experience. While teachers can promise each new cohort of students to believe that reflective writing is a positive experience, I now can tell my students that there is evidence to show that students do find it to be a positive experience. New students can be told that previous students found reflective writing to be beneficial, but that it is not an instant effect. The research shows that students talk about the benefits as a 'long term' result. Most particularly, the students who participated in the research have indicated that one of the benefits of reflective writing is the ability to 'focus', to 'reflect on what [they] may need to improve on', to 'organise what [they have] learnt', and to 'see how [they have] developed. From this research, I have learned that the pedagogy of reflective writing must include structured sessions that reinforce the idea of student consciousness of their own personal and professional development.

\section{Uniformity of experience}

In my clinical program, there are a variety of external placements as well as the internal Clinic where students might be placed. This is not unusual. One consequence of this is that students gathered together in one discussion class may collectively be undergoing a wide variety of placement experiences. Their responses 
to discussion topics will therefore be strongly nuances according to the environment in which they are placed. Some students will be placed in an environment with a strong individual client focus (especially in the Clinic). Others will have a law reform focus or an administrative focus. Some responses serve as a reminder that the clinical teacher must be deliberately and consciously inclusive of all students in all types of placements in all classes. This means checking with students in the discussion group whether they feel that the topic is relevant to their particular placement. In this way, students can be guided as to how they can interpret the theme of the discussion to match their placement experience. For example, a student placed at an external agency may have to consider who the 'clients' of the agency are. My research has taught me that clinical teachers must always be mindful of the variety of student placement experiences, and actively ask students in each class to consider how the discussion topic is relevant to their individual placements.

\section{Reflection-in-action}

A number of students said that they already either keep a journal or engage in some sort of reflective activity. Others observed that the requirement to reflect intruded into the actual placement tasks. Some students expressed frustration in relation to the written aspect of reflection. It is considered necessary to develop reflective writing pedagogy to include class time that assists student understanding that reflective writing can facilitate thinking skills and also to highlight the difference 
between the reflection in which some students already engage and the deeper reflection that is now required of them.

The clarification of the purpose of reflective writing must be effected early in the course. It is also necessary to clarify for students that reflective writing is more than self-evaluation. ${ }^{37}$ Some students appear to regard reflection as an end in itself rather than a tool for guiding action. ${ }^{38}$

I provide students with prompts to stimulate reflection but it is possible that when it comes to completing reflective writing for assessment, some students do not use them. Including the prompts in the actual assessment instructions will facilitate deeper reflection and hopefully eliminate student frustration. Instructions for assessable reflective writing tasks should include reflection 'prompts' which encourage and stimulate critical dialogic reflection.

One student noted that '[t]he formal nature of this reflection has made me more conscious of my reflections. Whereas before they were a natural occurrence, now I think more about thinking.' It is likely that this is not a flippant remark. This student is suggesting that the very process of thinking, or considering and reflecting can be structured. It would be useful to incorporate this discourse into reflective writing pedagogy by saying to students: think about the way you think. Do you think like everyone else? Why not? How do you know? What influences the way you think? E.g. background,

\footnotetext{
${ }^{37}$ Kennison, M (2012) ‘Developing Reflective Writing as Effective Pedagogy', Nursing Education Perspectives Vol 33, No 5, 306.

${ }^{38}$ Freire, P (2007) Pedagogy of the oppressed. New York: Continuum, cited in Kennison, above, 306.
} 
heritage, age, responsibilities, fears, goals etc. Clinical teachers should actively ask students to consider the way that they think and what external influences exist in relation to the way they solve problems and confront dilemmas.

\section{PART VI: CONCLUSION}

This article provides an analysis of the results of formal research that was conducted into student perceptions of reflective writing in the clinical legal education context. The research had a dual purpose. Its first purpose was to investigate whether students perceived any benefit from reflective writing. The second purpose was to investigate the difficulties that students actually encountered in writing in a way that is particularly different to other forms of academic assessment. This article has analysed the results of the first objective. A further article analyses the results of the second objective.

The objective of this research was to ascertain whether student perceptions of reflective writing match faculty perceptions of the benefits of reflective writing in clinical legal education. Qualitative research has revealed that perceptions differ amongst the student cohort and that not all students perceive benefit from reflective writing in the clinical legal education context. However, the majority of students surveyed for this research indicated an appreciation of reflective writing as an enhancement to a clinical placement. Their responses have generated a series of 
recommendations that clinical legal educators might consider in their own pedagogical practices.

This article has described and explained the first objective of a large research project: to ascertain the perceived benefits of reflective writing from a student perspective. The research has revealed that students perceive a variety of benefits, most particularly the development of critical thinking skills and as a tool for personal and professional development. As a consequence of this research, I have developed an improved pedagogy of reflective writing in the clinical legal education context. Part $\mathrm{V}$ offers several suggestions and recommendations as to how this improved pedagogy might be achieved. These recommendations are relevant not only in law schools, but in any discipline where reflective writing is embedded within the curriculum. Like my earlier article, this one has been written with a view to sharing my experiences so that other teachers of similar courses might benefit from my research and also from my conclusions and recommendations. 